\title{
Measurements of desert dust optical characteristics at Porte au Sahara during SAMUM
}

\author{
By W. VON HOYNINGEN-HUENE ${ }^{1 *}$, T. DINTER ${ }^{1}$, A. A. KOKHANOVSKY ${ }^{1}$, J. P. BURROW S ${ }^{1}$, \\ M. WENDISCH ${ }^{2}$, E. B IERW IRTH ${ }^{2}$, D. MÜLLER ${ }^{3}$ and M. DIOURI ${ }^{4}, \quad{ }^{1}$ IUP University of Bremen, \\ Bremen, Germany; ${ }^{2}$ Institute of Physics of Atmosphere, University Mainz; ${ }^{3}$ Institute of Tropospheric Research; \\ ${ }^{4}$ University of Oujda, Oujda, Morocco
}

(Manuscript received 29 December 2007, in final form 30 October 2008)

\begin{abstract}
Main optical characteristics of desert dust, such as phase function and single scattering albedo, have been derived from combinations of sun-/sky-radiometer and satellite measurements during the SAMUM experiment (10 May-10 June 2006) at the site Porte au Sahara $\left(30.237^{\circ} \mathrm{N}, 5.607^{\circ} \mathrm{W}\right)$ in South Morocco. Scattering phase functions have been retrieved using combined data of spectral aerosol optical thickness (AOT) and spectral sky brightness in the almucantar, considering non-spherical light scattering. Intercomparisons of modelled top-of-atmosphere (TOA) reflectance with satellite observations of the Medium Resolution Imaging Spectrometer (MERIS) and Scanning Imaging Absorption Spectrometer for Atmospheric Chartography () instrument have been used for the estimation of spectral single scattering albedo. For the radiative transfer calculations scattering phase functions and AOT from ground-based observations have been used. The spectral single scattering albedo ranges from 0.93 in the blue to 0.98 at $753 \mathrm{~nm}$.
\end{abstract}

\section{Introduction}

According to Intergovernmental Panel on Climate Change (IPCC, 2007) the contribution of mineral dust to radiative forcing is unclear in magnitude and sign. This is mainly due to the uncertainties in the optical characteristics of mineral dust, for example, scattering phase function and spectral single scattering albedo. Levy et al. (2007) showed the relevance of aerosol phase function for the remote sensing of aerosols using Moderate Imaging Spectrometer (MODIS) instrument. There is a large difference in the use of phase functions in MODIS between collections 4 and 5 retrievals. Now phase functions for desert dust are used, based on spheroidal particle shape by Dubovik et al. (2006) rather than the spherical shape approximation. For several other regions also the coarse particle fraction in the aerosol models has been increased, to give comparable retrievals with ground-based AERONET results. Single scattering albedo of mineral dust ranges between 0.9 and 0.99 for the wavelength of $0.67 \mu \mathrm{m}$, modifying significantly retrievals of aerosol optical thickness (AOT), depending on choice of the value. Remote sensing of desert dust is made for instance by Hsu et al. (2004),

\footnotetext{
${ }^{*}$ Corresponding author. e-mail: hoyning@iup.physik.uni-bremen.de DOI: $10.1111 /$ j.1600-0889.2008.00405.x
}

Levy et al. (2007) and Dinter et al. (2008). It requires look-uptables (LUTs) to retrieve AOT, obtained by radiative transfer calculations, using basic radiative properties of the aerosol, like phase function and single scattering albedo (SSA) and the spectral surface reflectance.

Thus experimental studies of aerosol phase functions and single scattering albedo of desert dust are required to reduce the uncertainty in these optical characteristics and in the results of radiative transfer modelling for evaluating radiative forcing and remote sensing. Therefore, within the SAMUM experiment closure measurements of ground-based AOT, spectral sky brightness and satellite radiance have been performed to derive aerosol phase functions and single scattering albedo of desert dust in the vicinity of a major dust source region. Spectral surface reflectance is contributed by air-borne (Bierwirth et al., 2008) and satellite (Dinter et al., 2008) observations.

A key characteristic is the aerosol phase function. Uncertainties in phase function have consequences on other radiative characteristics in remote sensing. The errors in the phase function have direct influence on retrieved AOT, single scattering albedo and the bi-directional reflection functions (BRDF) of the surface. Therefore, the first focus of this specific SAMUM contribution is the determination of phase functions of desert dust. The resulting phase functions will be used for the generation of LUTs for the aerosol retrieval in Dinter et al. (2008) and the derivation of single scattering albedo in this contribution. 


\section{Description of closure measurements}

The derivation of phase functions and single scattering albedo can be obtained by either laboratory measurements or indirectly by radiative closure measurements. Laboratory measurements of phase functions are made with polar nephelometers (Volten et al., 1996, 2001), single scattering albedo is determined by combined nephelometer and absorption photometer measurements (Müller et al., 2008a). These approaches use aerosol samples for the analysis. Indirect radiative closure studies use quasi-simultaneous measurements of different radiation characteristics and evaluate them by inverse retrieval techniques. The advantage of indirect methods is that the aerosol will not be influenced by the sampling process as it is the case for laboratory investigations. Thus inverse methods, analysing combined spectral sunphotometer and sky brightness measurements, have been developed to powerful tools for the retrieval of aerosol phase functions (Wendisch and von Hoyningen-Huenen, 1994; von Hoyningen-Huene and Posse, 1997; Dubovik et al., 2002). Retrievals with measurements under desert dust conditions have been made by von Hoyningen-Huene et al. (1999), Catrall et al. (2003) and Dubovik et al. (2006) and considered non-spherical light scattering for the dust particles. Additionally satellite measurement of top-of-atmosphere (TOA) reflectance enables the estimation of single scattering albedo.

Such closure measurements, consisting of spectral sunphotometer measurements of direct solar radiation, angular and spectral sky radiance in the almucantar have been made during SAMUM using a CIMEL CE 318 sunphotometer at the site 'Porte au Sahara' $\left(30.237^{\circ} \mathrm{N}, 5.607^{\circ} \mathrm{W}\right)$, a desert like plane with free horizon in South Morocco, $30 \mathrm{~km}$ south of the city Zagora. The measurements have been made within the time period 12 May 200607 to June 2006.

The CIMEL instrument has a field of view (FOV) of $1.2^{\circ}$. The instrument is equipped with original interference filters and also with additional filters to block light outside the band-pass region. The additional blocking filters have been essential especially for the two ultraviolet (UV) channels (0.34 and 0.38 $\mu \mathrm{m})$ and the near infrared (NIR) channel at $1.02 \mu \mathrm{m}$. The instrument was calibrated by numerous Langley-plot measurements at various locations and at various temperature conditions. Since the CIMEL instrument has no temperature stabilization, Langley plots have been made at Mt. Zugspitze and in Bremen and the extraterrestrial instrument intensity $i_{0}(\lambda)$ has been obtained as a function of instrument temperature. Thus, a temperature-dependent calibration function was derived, to minimize virtual diurnal cycles. Linear temperature sensitivities have to be accounted for all channels. The largest temperature sensitivities are in the UV and the NIR channels.

Direct solar light has been measured for the determination of spectral AOT. Sky radiance measurements have been started specifically for low as possible Sun elevations to obtain information on large scattering angles. The automatic CIMEL mea-
Table 1. Channels of the different instruments and measurement regimes

\begin{tabular}{lll}
\hline Direct Sun & $\begin{array}{l}\text { CIMEL } \\
\text { sky brightness }\end{array}$ & $\begin{array}{l}\text { MERIS } \\
\text { TOA reflectance }\end{array}$ \\
\hline 0.340 & & \\
0.380 & & 0.412 \\
& & 0.443 \\
0.440 & 0.440 & 0.490 \\
0.500 & & 0.510 \\
& & 0.560 \\
& & 0.620 \\
0.670 & 0.670 & 0.665 \\
& & 0.688 \\
& & 0.708 \\
& & 0.753 \\
0.870 & 0.870 & 0.770 \\
0.940 & & 0.865 \\
1.020 & 1.020 & 0.885 \\
\hline
\end{tabular}

surement protocol does not support sky measurements at such low Sun elevations, therefore such measurements have been performed manually. For intercomparisons and retrievals of AOT (cf. Dinter et al., 2008) the TOA reflectance of Medium Resolution Imaging Spectrometer (MERIS) observations in the reduced resolution (RR) mode of 13 spectral channels from blue to NIR from ESA near real time server at Kiruna have been used. The available spectral channels for all three types of measurements are presented in Table 1.

The results of the measurements and their application in the intercomparisons are described in the next sections.

\section{Aerosol optical thickness}

Sunphotometer measurements of direct solar radiation have been performed to derive spectral AOT as basic information for (1) the validation of AOT retrievals from MERIS observations (Dinter et al., 2008) and (2) the radiative transfer calculations to retrieve further optical aerosol characteristics of desert dust.

Desert dust observed at low Sun elevations gives rise to significant light contribution from the aureole into the FOV. This effect of scattered light needs to be considered, since the aureole contribution leads to a significant reduction of AOT for large air mass factors $M$, leading to a virtual diurnal cycle. With the used phase function the aureole effect in the NIR channels (at 1.02 and $0.87 \mu \mathrm{m}$ ) is about $5 \%$ of the measured signal at an air mass of 3.2 and negligible for an air mass of 1.2. In the UV (at $0.34 \mu \mathrm{m}$ ) it is $17 \%$ for the air mass of 3.2 and $2 \%$ at 1.2 . Under 
these desert conditions and an air mass of 3.2 an unconsidered aureole reduces the AOT in the UV at $0.34 \mu \mathrm{m}$ by $11 \%$.

Instead of the apparent total optical thickness $\delta_{\text {app }}(\lambda)$

$\delta_{\text {app }}(\lambda)=\frac{1}{M} \ln \frac{i_{0}(\lambda)}{i(\lambda)}$,

the aureole corrected optical thickness is determined, using a single scattering approximation for the aureole.

$\delta(\lambda)=\frac{1}{M} \ln \frac{i_{0}(\lambda)}{i(\lambda)-i_{\text {diff }}(\lambda)}$

with

$i_{\text {diff }}(\lambda) \approx i_{0}(\lambda) \int_{\text {FOV }} \mathrm{e}^{-\delta_{\text {app }}(\lambda) M} M p_{H}(\theta) \mathrm{d} \Omega$.

$i(\lambda)$ is the measured solar intensity by the instrument at air mass $M i_{0}(\lambda)$ is the extraterrestrial intensity, derived from Langley plots. $i_{\text {diff }}(\lambda)$ is the diffuse sky radiation according the approximative calculation of diffuse radiation for the given apparent optical thickness and air mass factor range within the FOV of the CIMEL instrument of $1.2^{\circ}$ with the solid angle $\mathrm{d} \Omega \cdot p_{H}(\theta)$ is the atmospheric phase function with the scattering angle $\theta$. The estimate for the phase function has been taken from the averaged phase function, derived from the almucantar measurements in Section 4. For the approximation of the diffuse sky light we used the simple sky light equation for almucantar geometry given by Volz (1954). This aureole correction is for a wide range of AOT and M comparable with that of Kinne et al. (1997) and Russell et al. (2004).

Since the CIMEL has no temperature stabilization, the measured signal is also a function of instrument temperature $t$. We need to correct the measured values to a defined reference temperature $t_{\text {ref }}$, for which the Langley-plot calibration is valid.

$i(\lambda)=i(\lambda, t)\left[1+t_{\mathrm{c}}\left(t-t_{\mathrm{ref}}\right)\right]$.

The $t_{\mathrm{c}}$ values are characteristic for the single spectral channels and have values from $0.03 \%$ per ${ }^{\circ} \mathrm{C}$ for visible channels and increase to $0.3 \%$ per ${ }^{\circ} \mathrm{C}$ for $1.02 \mu \mathrm{m}$ and even $0.5 \%$ per ${ }^{\circ} \mathrm{C}$ for $0.340 \mu \mathrm{m}$. For measurements in the desert region of Morocco with diurnal temperature changes from 20 to $45^{\circ} \mathrm{C}$ the temperature correction was essential to get correct spectral behaviour of AOT. The AERONET processing only considers the temperature sensibility of the $1.02 \mu \mathrm{m}$ channel with $0.25 \pm 0.05 \%$ per ${ }^{\circ} \mathrm{C}$. For other channels no temperature correction is applied (Holben et al., 1998).

The air mass factor $M$ is obtained with Kasten and Young (1989) considering atmospheric curvature and refraction.

The AOT $\delta_{\text {Aer }}$ is derived from corrected total optical thickness $\delta$ by making corrections for Rayleigh scattering $\delta_{\text {Ray }}$ and gas absorption.

$\delta_{\text {Aer }}(\lambda)=\delta(\lambda)-\delta_{\text {Ray }}(\lambda)-\delta_{\mathrm{O}_{3}}(\lambda)-\delta_{\mathrm{H}_{2} \mathrm{O}}(\lambda)-\delta_{\mathrm{NO}_{2}}(\lambda)$

Gas absorption is considered for ozone for the channels 0.5 and $0.67 \mu \mathrm{m}$. The channel $0.94 \mu \mathrm{m}$ is not considered for AOT

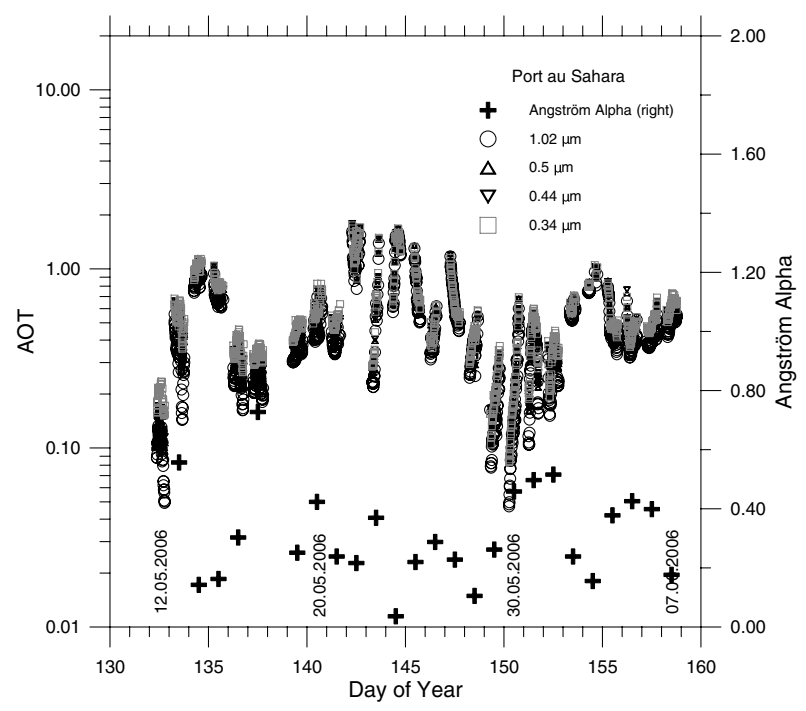

Fig. 1. Time-series of the aerosol optical thickness for four wavelengths and average Angström Alpha of the SAMUM experiment at the site Porte au Sahara.

determination because of its contamination with strong water vapour absorption. For the desert case in Morocco $\mathrm{NO}_{2}$ absorption is not considered.

The estimation for the error of AOT measurements gives 0.02 . Thus, the relative error is $10 \%$ for clean days and drops to $2 \%$ for very dusty cases.

With this approach spectral AOT is determined for the time period of SAMUM. The time-series of AOT is presented in Fig. 1. As an example of spectral behaviour of AOT the data of 19 May 2006 are presented in Fig. 2. All days of the period have been characterized by desert dust aerosol with more or less different AOTs. As can be seen in Fig. 1 strong dust events appeared between 22 May and 26 May. Also cleaner days show the typical flat spectral slope of dust aerosol. The Angström parameter $\alpha$ is also shown in Fig. 1. For the most days Ångström $\alpha$ is low (0.03-0.4). Few days with advection of different air masses make exceptions and are characterized by larger $\alpha$. The values of $\alpha$ show that the AOT of this period is mainly determined by the mineral dust. Thus, the data can be used to derive further optical characteristics of desert dust, such as phase function and single scattering albedo.

\section{Retrieval of aerosol phase functions}

For the retrieval of aerosol phase functions three steps are required: (1) measurements of sky radiance in the almucantar and their preparation for the comparison with results of radiative transfer calculations; (2) spectral AOT data (Section 3) and (3) a retrieval procedure for the inversion of aerosol phase functions. For the latter one the coupled inversion radiation transfer 


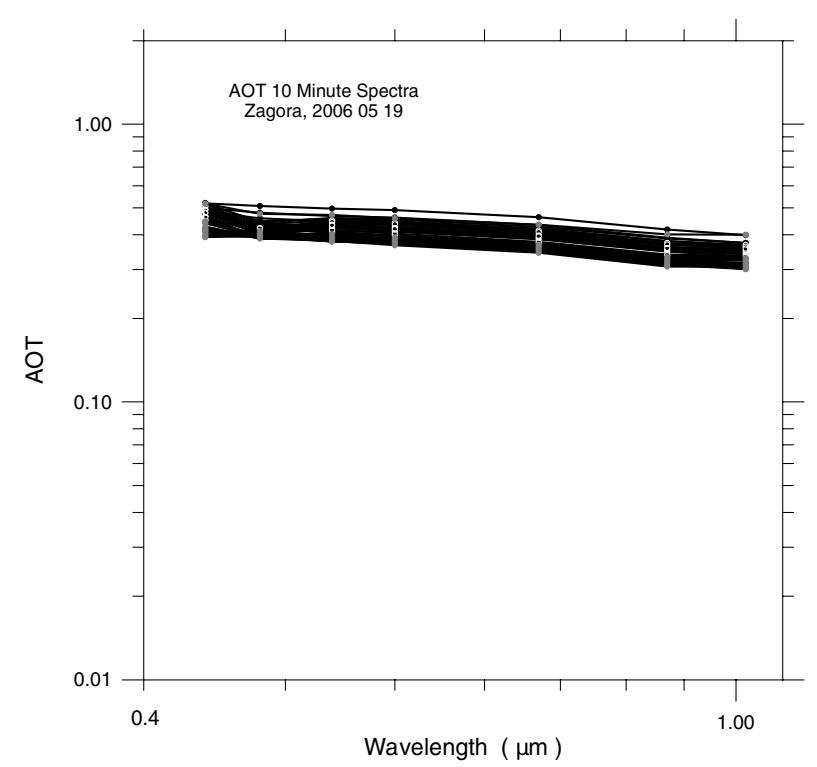

Fig. 2. Typical AOT spectrum for the measurements at the site Porte au Sahara. Example, 19.05.2006, all measurements: grey dots—morning, white circles—-middle of day, black dots— afternoon measurements.

(CIRATRA; Wendisch and von Hoyningen-Huenen, 1994; von Hoyningen-Huene and Posse, 1997) approach is used.

\subsection{Preparation of experimental data}

In addition to the measurements of the spectral optical thickness of aerosol $\delta_{\text {Aer }}(\lambda)$ four channels of the instrument, see Table 1, are used to measure the sky brightness and the aureole in the almucantar (that means at the same elevation as the Sun) at 27 different azimuth angles $\psi$ in the range of $3^{\circ}-180^{\circ}$. Almucantar measurements can only be evaluated, if the sky in all directions is totally free of clouds. In the first step the so-called unnormalized sky brightness can be determined from the measured sky signals of the instrument $i_{\text {Sky }}$

$L_{\text {Sky }}(\lambda, \theta)=\frac{1}{M} \frac{\xi i_{\text {Sky }}(\lambda, \theta)}{i_{0}(\lambda) \exp (-\delta(\lambda) M)}$,

where $\xi$ is the product of the ratio of FOV of instrument to that of Sun with the absolute calibration constant $\frac{\omega_{\text {Obj }}}{\omega_{\text {Sun }}} C_{\text {cal }}(\lambda)$. It is not important, if normalized functions (eq. 8) are used. $i_{\text {Sky }}(\lambda$, $\theta)$ is the measured sky brightness, $i_{0}(\lambda)$ - the instrument solar calibration, $\delta(\lambda)$ is the total optical thickness from Section 3 and $M$ the air mass factor. $\theta$ is the scattering angle, obtained as

$\theta=\arccos \left(\sin ^{2}\left(h_{\mathrm{s}}\right)+\cos ^{2}\left(h_{\mathrm{s}}\right) \cos (\psi)\right)$

from solar elevation $h_{s}$ and azimuth $\psi$.

There are two reasons for the use of a normalization of sky radiance data: (1) absolute sky radiance requires a precise ab- solute calibration. Because of different unknown properties of the instrument this may be a significant source of errors. (2) The results of calculation of sky radiance using radiative transfer codes depend on the accuracy of input data (e.g. solar spectrum, simulated filter bands).

To compare such measurements with radiative transfer calculations both the radiometer and the radiative transfer model must have the same 'calibration' conditions. To avoid discrepancies from different 'calibration' conditions, we normalize the measured sky brightness.

$p_{\text {Sky }}(\theta, \lambda)=L_{\text {Sky }}(\theta, \lambda) / \int_{0}^{\pi} L_{\text {Sky }}(\theta, \lambda) \sin \theta \mathrm{d} \theta$

from the measured sky radiances $L_{\text {Sky }}(\theta, \lambda)$. The normalization removes the influence of calibration, uncertainties in knowledge of FOV and relative optical air mass. Therefore, the normalization makes all brightness measurements comparable. This function contains the scattering properties of the sky including the multiple scattering. However, the normalization leads to a loss of information on single scattering albedo. Therefore, single scattering albedo needs to be determined from a comparison with well-calibrated radiation quantities in a separate step, see Section 5.

The normalization requires the integration of the sky radiance in the complete interval of scattering angles between $0^{\circ}$ and $180^{\circ}$. The CIMEL instrument performs the measurements in the azimuth range of $3^{\circ}$ and $180^{\circ}$, for example, scattering angle $\theta=180^{\circ}-2 h_{o}$, with $h_{o}$ - the solar elevation. To extend the measured range of scattering angles to the required one of $0^{\circ}$ and $180^{\circ}$, the measured sky brightness has to be extrapolated in the forward and backward scattering regions. To extrapolate the forward range to $\theta=0^{\circ}$ we fit a Henyey-Greenstein function to the measurements in the $\theta$-range of $3-10^{\circ}$. To extrapolate the backscattering range to $\theta=180^{\circ}$ we fit the Heney-Greenstein function from the minimum value of the sky measurement (at about $120^{\circ}$ ) to the largest measurable scattering angle at $\theta_{\mathrm{Max}}=$ $180^{\circ}-2 h_{\mathrm{s}}$.

To reach large scattering angles covered by the measurements low as possible Sun elevations have been selected. The almucantar measurements have been started at about $h_{\mathrm{s}}=5^{\circ}$, if clear sky conditions for measurements prevailed. The maximum scattering angles close to $170^{\circ}$ were obtained. This is an essential increase in angular information compared with standard CIMEL operation, used in AERONET and starting at $M \leq$ 4 , which is reaching $150^{\circ}$ in both, almucantar and principle plane.

Some examples of normalized sky brightness measurement for all four sky wavelengths of the CIMEL instrument are shown in Fig. 3 for the 19 May 2006. If normalization conditions are fulfilled and the sky conditions during the day are stable all measurements for the same wavelength should have the same curve. 


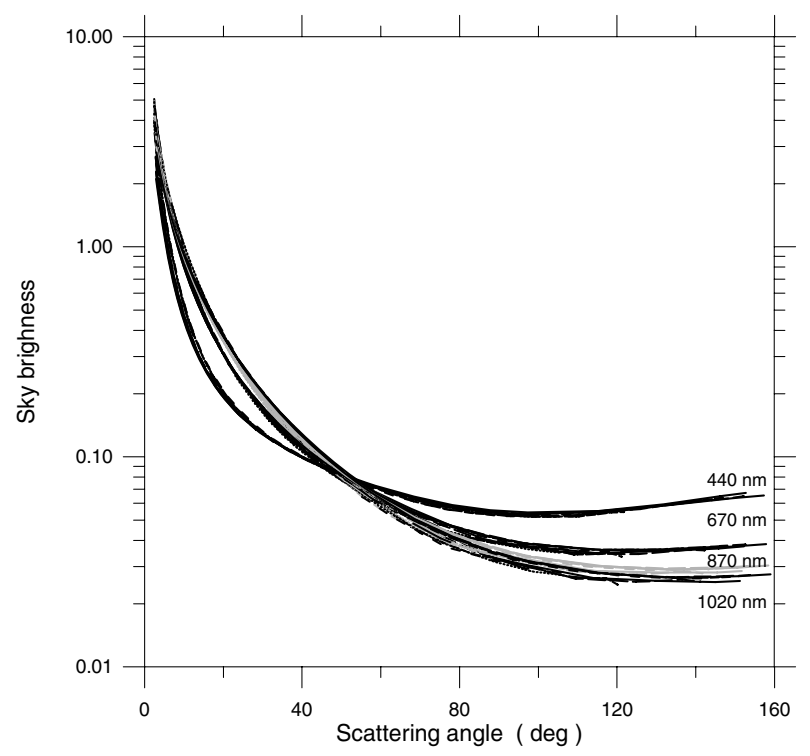

Fig. 3. Normalized sky brightness from almucantar measurements for the four sky channels of the CIMEL instrument at the site Porte au Sahara. Example, 19.05.2006, all measurements. The channels are centred at 1.02, 0.87, 0.67 and $0.44 \mu \mathrm{m}$.

\subsection{Retrieval of phase functions of desert dust}

For the retrieval of the phase functions from almucantar and spectral AOT the CIRATRA approach (Wendisch and von Hoyningen-Huenen, 1994; von Hoyningen-Huene and Posse, $1997)$ is used. The approach consists of several main steps:

(1) Inversion of an optically equivalent aerosol size distribution from spectral AOT and sky brightness aureole for a range of refractive indices from 1.31 to 1.70 .

(2) Calculation of aerosol phase function, using the inverted size distributions and a selected scattering database. Available scattering databases are: Mie theory with spherical particles, the semi-empirical scattering theory of Pollack and Cuzzi (1980) and $T$-matrix data of Mishchenko et al. (2000).

(3) Radiative transfer calculations with the corresponding spectral optical thickness, composed from AOT and Rayleigh scattering, the atmospheric phase function, consisting of calculated aerosol phase function of the previous step and Rayleigh phase function, an assessment for the surface albedo and a single scattering albedo. For the radiative transfer calculations the approach of Nakajima and Tanaka (1988) is used. The radiative transfer calculation can be made either for the geometry of the almucantar or the satellite observation. In the case of retrieval of aerosol phase function the almucantar geometry is selected. The results of the radiative transfer calculation is normalized in the same way as described in equation (8).

(4) Comparison of the results of radiative transfer calculation with the normalized sky brightness from almucantar measurement.
The above steps are made in a loop, varying the real part of refractive index, and parameters for the selected scattering theory looking for the best approximation between measured and calculated normalized sky brightness. The result with the minimal root mean square deviation (RMSD) between both sky brightness distributions lead to the aerosol phase function, representing the existing radiation field.

The approach used by us deviates not in a significant way of the standard AERONET approach (Dubovik and King, 2000).

(1) We use normalized sky brightness data instead of absolute ones, because no absolute radiometric calibration of the sun-/sky-radiometer is required (The absolute calibration is a difficult task and may be not stable under all working conditions of the radiometer). With the normalization of the sky radiance data in the measurements and radiative calculations we remove a significant error source. (2) The size distribution is inverted by both approaches. AERONET uses bi-modal lognormal distribution. This approach uses a 24-bin frequency distribution in a range of $r_{\text {low }}-r_{\text {up }}$ with the step d $\log r$ for a given refractive index, fitted to spectral AOT and aureole measurements. The 24-bin frequency distribution is more general than the bi-modal size distribution. In both cases the size distributions are fitted to the measured data and should be representative for the optical data. (3) In both approaches aerosol phase function is calculated, using Mie theory for spherical particles. (4) In the case of nonspherical particles (in our case RMSD for the Mie theory $>0.1$ ) other scattering theories are used: AERONET uses a mixture of spheroids with different aspect ratios. The frequency of aspect ratios is the empirical tuning of the AERONET approach to get a closer approximation to the measured sky radiance data. This approach uses the theory of Pollack and Cuzzi (1980), where three parameters are used to tune a closer approximation to the normalized sky brightness data of the measurements. In both approaches the closest approximation of measured data is used. Thus, both approaches come to similar results for the phase function.

The phase functions used here are normalized to the unit sphere, for example, divided by $4 \pi$ and have the unit $\mathrm{sr}^{-1}$.

Mie theory gave only large RMSD of about $20 \%$ compared with the other non-spherical scattering theories: Pollak and Cuzzi approach gave RMSD $<5 \%$ for the most cases. The T-matrix approach also gives lower RMSD than Mie theory. In our case the implemented database for $T$-matrix calculation, however is restricted in the range of size parameters and aspect ratio. Thus, the results here have larger RMSD than the Pollak and Cuzzi approach. Since Dubovik et al. (2006) use a database with extended size parameter range and larger range of aspect ratios we do not report results of the T-matrix approximation as it is made by Müller et al. (2008b).

The error for the retrieval of aerosol phase function is estimated with $0.003 \mathrm{sr}^{-1}$ for the backscattering region, which is for the values of 0.013 about $25 \%$. 


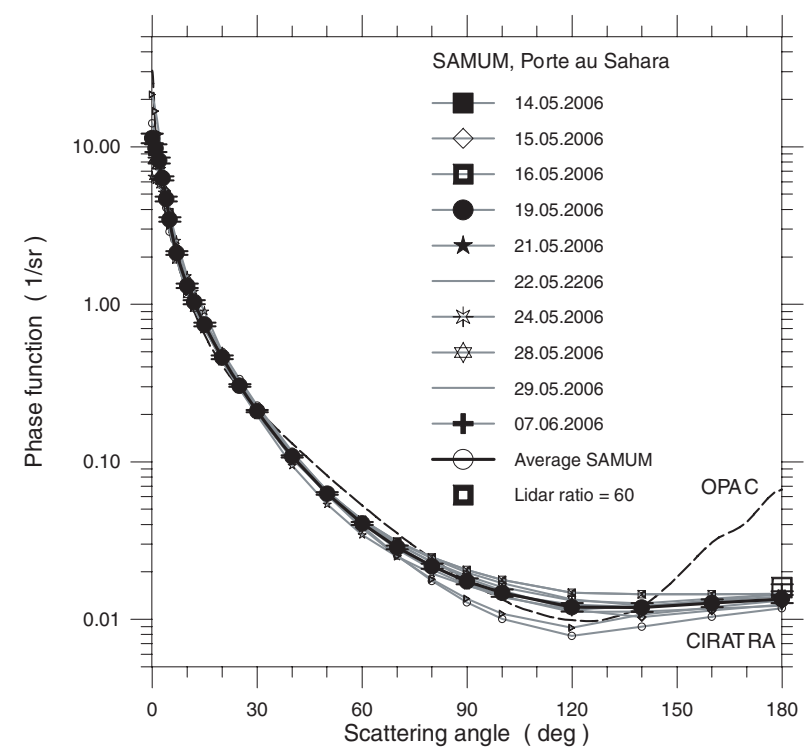

Fig. 4. Aerosol phase functions (single averaged results of the days of the period and the overall average with its standard deviation) of the SAMUM experiment for the $870 \mathrm{~nm}$ wavelength at the site Porte au Sahara. For comparison the phase function for desert aerosol of the OPAC model (Hess et al., 1998) is included.

Table 2. Overview of almucantar measurements with phase function retrievals and its number and availability of MERIS data

\begin{tabular}{llll}
\hline Date & $\begin{array}{l}\text { Number of } \\
\text { Almucatar }\end{array}$ & $\begin{array}{l}\text { AOT } \\
(0.5 \mu \mathrm{m})\end{array}$ & $\begin{array}{l}\text { MERIS } \\
\text { overflight }\end{array}$ \\
\hline 13 May 2006 & - & 0.47 & Yes \\
14 May 2006 & 8 & 1.08 & No \\
15 May 2006 & 4 & 0.72 & No \\
16 May 2006 & 7 & 0.36 & Yes \\
19 May 2006 & 16 & 0.40 & Yes \\
21 May 2006 & 8 & 0.43 & No \\
22 May 2006 & 2 & 1.17 & Yes \\
24 May 2006 & 2 & 1.29 & No \\
25 May 2006 & - & 1.35 & Yes \\
28 May 2006 & 9 & 0.43 & No \\
29 May 2006 & 6 & 0.13 & Yes \\
30 May 2006 & 2 & 0.14 & No \\
01 June 2006 & - & 0.33 & Yes \\
04 June 2006 & - & 0.46 & Yes \\
07 June 2006 & 8 & 0.59 & Yes \\
\hline
\end{tabular}

The most retrievals have been made for the CIMEL channel 2, e.g. wavelength $0.87 \mu \mathrm{m}$. The aerosol phase functions of desert dust for this wavelength, obtained for the smallest RMSD are presented in Fig. 4 and the average of the campaign is listed in Table 3. Table 2 gives the statistics of useful almucantar measurements of the different days.

All functions are almost flat in the backscattering region. This is confirmed by the lidar ratio of $\mathrm{LR}=55 \ldots 60$, which is in-
Table 3. Average dust phase function at Porte au Sahara during SAMUM

\begin{tabular}{lll}
\hline $\begin{array}{l}\text { Scattering } \\
\text { angle } \\
\left({ }^{\circ}\right)\end{array}$ & $\begin{array}{l}\text { phase function } \\
\left(\mathrm{sr}^{-1}\right)\end{array}$ & $\begin{array}{l}\text { Standard } \\
\text { deviation }\end{array}$ \\
\hline 0.0 & 11.355 & 0.78685 \\
1.0 & 9.7972 & 0.55881 \\
2.0 & 8.1915 & 0.35242 \\
3.0 & 6.3128 & 0.19349 \\
4.0 & 4.6691 & 0.15433 \\
5.0 & 3.4604 & 0.11849 \\
7.0 & 2.1194 & 0.05313 \\
10.0 & 1.3095 & 0.04128 \\
12.0 & 1.0302 & 0.02905 \\
15.0 & 0.7436 & 0.02121 \\
20.0 & 0.4598 & 0.01182 \\
25.0 & 0.3046 & 0.00599 \\
30.0 & 0.2096 & 0.00339 \\
40.0 & 0.1080 & 0.00153 \\
50.0 & 0.0629 & 0.00109 \\
60.0 & 0.0405 & 0.00088 \\
70.0 & 0.0286 & 0.00083 \\
80.0 & 0.0217 & 0.00080 \\
90.0 & 0.0174 & 0.00078 \\
100.0 & 0.0147 & 0.00077 \\
120.0 & 0.0119 & 0.00073 \\
140.0 & 0.0119 & 0.00076 \\
160.0 & 0.0127 & 0.00072 \\
180.0 & 0.0135 & 0.00079 \\
\hline & & \\
\hline & & \\
\hline
\end{tabular}

cluded in Fig. 4. Lidar ratios are taken from lidar measurement at Ouarzazate (Tesche et al., 2008) and for three days at the site Porte au Sahara (Heese et al., 2008). This deviates significantly from the desert dust model of Optical Properties of Aerosol Components (OPAC; Hess et al., 1998), based on spheres with Mie theory. Especially the deviation in the range of lateral and backscattering, using spherical particles causes misleading results in remote sensing studies, like apparent BRDF effects and apparent single scattering albedo.

Retrievals of phase function, using spheroids show a small peak at backscattering toward $180^{\circ}$ (Dubovik et al., 2006; Levy et al., 2007). We do not find this peak, if we combine lidar ratio and single scattering albedo of Section 5 with our retrievals, see Fig. 4. Within the error limits of $4 \%$ of the satellite data a backscattering peak is also not confirmed.

For radiative transfer calculations of smaller wavelength down to the UV the question for the spectral dependence of the aerosol phase function arises. Therefore, for selected days also data of the channel $0.440 \mu \mathrm{m}$ have been used. The results of the both wavelength 0.870 and $0.440 \mu \mathrm{m}$ are presented in Fig. 5 in comparison with the spectral results of Dubovik et al. (2006). Within the error limits of the inversions at both wavelengths no 


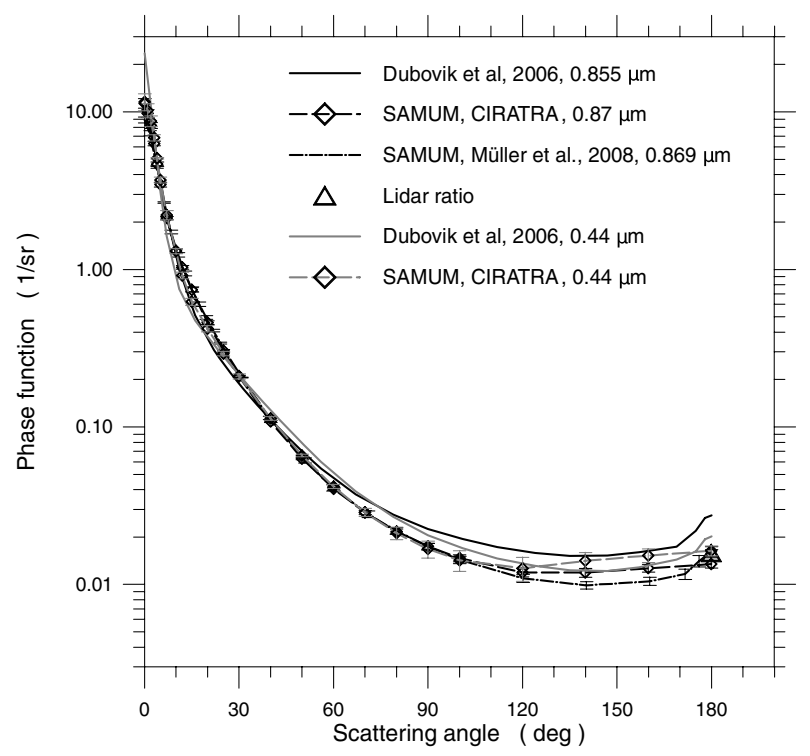

Fig. 5. Spectral aerosol phase functions for 19 May 2007 of the SAMUM experiment for the wavelength 440 and $870 \mathrm{~nm}$ at the site Porte au Sahara in comparison with the desert dust phase functions of Dubovik et al. (2006) and Müller et al. (2008b).

significant difference could be found, as well with the results of these inversions and the results of Dubovik et al. (2006). Therefore, we decide to use the aerosol phase functions derived for radiative transfer studies for shorter wavelength too.

\section{Estimation of spectral single scattering albedo}

The determination of the spectral single scattering albedo requires measured calibrated radiances, which can be compared with radiative model calculations, using measured spectral AOT and the obtained phase functions of desert dust. The reflectance measured by the MERIS instrument on board of ENVISAT is given with an accuracy of $4 \%$. MERIS has 15 channels within the range of $0.412-0.900 \mu \mathrm{m}$, where 13 channels are outside of strong gas absorption bands. The spatial resolution of MERIS is $1.2 \times 1.2 \mathrm{~km}^{2}$. Thus, comparison between modelled TOA reflectance, using ground-based aerosol characteristics from Sections 3 and 4 and measured TOA reflectance from satellite data can be performed. The geometry conditions for the overflights are known. If there are data of spectral surface reflectance, the only free aerosol parameter to achieve closure between modelled and measured TOA reflectance is the single scattering albedo. Since our normalized phase functions in the LUTs do not contain single scattering albedo $\omega_{0}$, we get a retrieval correctly for the 'scattering part' on AOT, without any information of $\omega_{0}$. And the same is valid for the surface reflectance. Using these data in RT modelling with $\omega_{0}=1$ leads to an overestimation of the TOA reflectance compared with the satellite measurements. We explained this difference as effect of absorption, because $\omega_{0}$

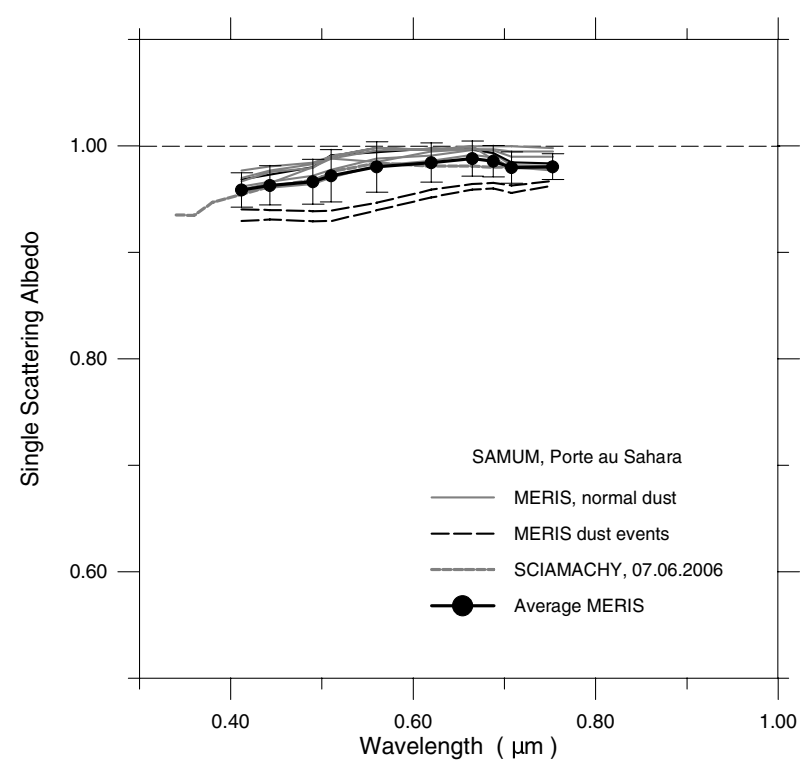

Fig. 6. Spectral single scattering albedo of desert dust, obtained from ground-satellite closure of TOA reflectance for the site Porte au Sahara during SAMUM experiment, using MERIS and SCIAMACHY TOA reflectance. Error bars are obtained from standard deviation.

is a linear factor in front of all scattering terms of the radiative transfer equation.

The spectral surface reflectance for the modelling is taken from retrievals by Dinter et al. (2008) for the site Porte au Sahara, using atmospheric correction of measured MERIS TOA reflectance. The results of the retrieval of the surface reflectance are compared with results of spectral albedo measurements in the spectral range of $0.370-1.0 \mu \mathrm{m}$ provided by air-borne spectral albedometer (Bierwirth et al., 2008).

For the calculation of Rayleigh scattering exact surface pressure and temperature have been considered, because surface elevation and temperature conditions change the contribution of Rayleigh scattering in the blue and UV significantly.

Finally the spectral single scattering albedo has been varied until modelled TOA reflectance agreed within 0.001 . The values of used spectral single scattering albedo can be taken as estimates of the desert dust. Table 2 gives an overview of days, where ground-based data and MERIS overflights existed. Useful days have been 19, 22, 29 May and 07 June 2006. 22 May was the day with the largest AOT (1.17), and 29 May has the lowest AOT (0.13). The results of the estimation of spectral single scattering albedo are presented in Fig. 6. Numerical values of spectral single scattering albedo are given in Table 4. Single scattering albedo is changing with wavelength. The lowest values have been found for the channel $0.412 \mu \mathrm{m}$ with 0.95 . Single scattering albedo increases with increasing wavelength to 0.98 . For strong dust events (at 22 May 2006) significantly decreased values have been obtained, see corresponding column in Table 4 or dashed lines in Fig. 6. Similar values one obtains for 25 May 2006, 
Table 4. Average single scattering albedo of the measurements at Porte au Sahara during SAMUM campaign

\begin{tabular}{lll}
\hline $\begin{array}{l}\text { Wavelength } \\
(\mu \mathrm{m})\end{array}$ & $\begin{array}{l}\text { SAMUM average } \\
\text { all cases }\end{array}$ & $\begin{array}{l}\text { Dust events } \\
\delta_{\text {Aer }}<1.0\end{array}$ \\
\hline 0.412 & $0.958 \pm 0.02$ & $0.935 \pm 0.02$ \\
0.443 & $0.963 \pm 0.02$ & $0.935 \pm 0.02$ \\
0.490 & $0.966 \pm 0.02$ & $0.933 \pm 0.02$ \\
0.510 & $0.972 \pm 0.02$ & $0.935 \pm 0.02$ \\
0.560 & $0.980 \pm 0.02$ & $0.943 \pm 0.02$ \\
0.620 & $0.984 \pm 0.02$ & $0.955 \pm 0.02$ \\
0.665 & $0.988 \pm 0.02$ & $0.962 \pm 0.02$ \\
0.688 & $0.985 \pm 0.02$ & $0.962 \pm 0.02$ \\
0.708 & $0.979 \pm 0.02$ & $0.959 \pm 0.02$ \\
0.756 & $0.980 \pm 0.02$ & $0.964 \pm 0.02$ \\
\hline
\end{tabular}

if phase functions of 22 May are used. A similar tendency of reduction of single scattering albedo for strong dust episodes is presented in Petzold et al. (2008).

The error bars in Fig. 6 and in Table 4 are estimated from standard deviation of all retrievals of spectral single scattering albedo. Since the SSA is determined from the fit of modelled TOA reflectance to measured ones (MERIS), this impact on SSA is $4 \%$. The larger error sources are in the input data for the radiative modelling, such as surface reflectance as the main error source. Assuming an error of $10 \%$ for the error of surface reflectance data, the effect in TOA reflectance is spectrally different: about $2 \%$ in the blue and about $5 \%$ in the red, if we do not consider errors in AOT and phase function. According to error propagation we would come to $6 \%$ in the blue and $9 \%$ in the red part of the spectrum.

The same method is also applied to TOA reflectance observations of the Scanning Imaging Absorption Spectrometer for Atmospheric Chartography (SCIAMACHY)instrument on board of ENVISAT. The SCIAMACHY reflectance in the range of $0.443-0.753 \mu \mathrm{m}$ is compared with that of the MERIS instrument to ensure a correct calibration. Since SCIAMACHY gives TOA reflectance within the spectral range of $0.240-2.3 \mu \mathrm{m}$ with a spatial resolution of $30 \times 60 \mathrm{~km}^{2}$, the radiative transfer calculations are made starting at $0.340 \mu \mathrm{m}$ and are compared with the SCIAMACHY data, cf. Fig. 7. We choose three additional channels at $0.340,0.360$ and $0.380 \mu \mathrm{m}$ for the determination of single scattering albedo. The large footprint of SCIAMACHY includes different surface conditions, thus the selection of representative spectral surface albedo from air-borne measurements for the UV wavelength is difficult. The values decrease to the UV to a value of 0.91 . However, the uncertainty of surface albedo for $0.340 \mathrm{~nm}$ of the large footprint of SCIAMACHY gives error estimates of \pm 0.03 .

The main uncertainty within this approach is the heterogeneity of the spectral surface albedo. The values have been taken from retrievals of MERIS observations and air-borne mea-

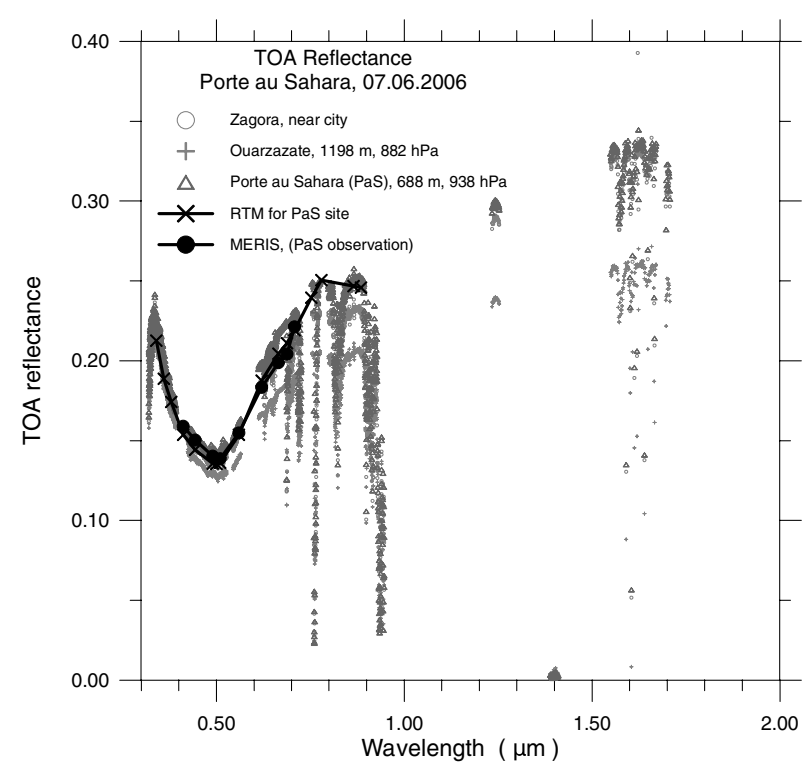

Fig. 7. Measured spectra of TOA reflectance of SCIAMACHY and MERIS in comparison with RTM results fitting single scattering albedo for UV channels for the site Porte au Sahara during SAMUM experiment.

surement and should correspond with the location of the site, where the ground-based AOT and phase function have been obtained. Within the spectral range of $0.412-0.865 \mu \mathrm{m}$ satellite retrieval and air-borne data are coinciding. For wavelength below $0.412 \mu \mathrm{m}$ the spectrum is extended using air-borne data.

The found values are significantly higher than values of Sokolik and Toon (1999). The found values are closer to data of Catrall et al. (2003). They show a decrease of single scattering albedo to the UV.

\section{Conclusions}

Based on the combination of ground-based sky radiance, spectral AOT and space-borne TOA reflectance measurements the main optical aerosol characteristics of desert dust for the radiative transfer have been derived for the application with MERIS observations (Dinter et al., 2008).

For the retrieval of phase functions of desert dust nonspherical light scattering needed to be considered. The use of spherical particles (Mie theory), as it is made in the OPAC dust models (Hess et al., 1998), gives strong deviations of phase functions in the range of $120^{\circ}-180^{\circ}$ scattering angle. This has consequences on quantities derived by remote sensing, like single scattering albedo of aerosol and BRDF of the ground.

The light scattering of non-spherical particles, approximated by the semi-empirical theory of Pollack and Cuzzi (1980), gives similar results as $T$-matrix approaches, assuming mixtures of spheroids as it is done by Dubovik et al. (2006), Levy et al. (2007) and Müller et al. (2008b). The phase functions of all approaches do not give the strong asymmetric behaviour of Mie theory. With 
our approach we found no indication for a significant peak at the scattering angle $=180^{\circ}$, as it is given by the spheroids. Especially sky brightness measurements at low Sun elevations below $10^{\circ}$ and the lidar ratio of 60 (cf. Tesche et al., 2008) support this finding.

Spectral single scattering albedo has been estimated from modelling TOA reflectance and intercomparison with satellite observations. The UV value at $0.340 \mu \mathrm{m}$ is found with 0.91 and 0.95 for $0.412 \mu \mathrm{m}$, rising up to 0.98 at $0.753 \mu \mathrm{m}$. Strong dust events give decreased single scattering albedo. Our values are at the upper limit of data, presented by Petzold et al. (2008), but they agree in spectral behaviour and magnitude with results of desert dust, given by Catrall et al. (2003). Compared with our findings the OPAC desert dust models underestimate the single scattering albedo significantly.

\section{Acknowledgments}

This work is supported by following sponsors: (1) the SAMUM research group of the German Science Foundation (DFG) under Grant FOR 539; (2) the state of Bremen and the University of Bremen and the ACCENT network of European Commission. The authors like to thank ESA for providing MERIS and SCIAMACHY L1 data for ground-satellite intercomparisons. Robert Levy from NASA GSFC contributed data of phase functions of the MODIS dust model. Birgit Heese supported us with unpublished lidar data of Porte au Sahara.

\section{References}

Bierwirth, E., Wendisch, M., Ehrlich, A., Heese, B., Tesche, M. and coauthors. 2008. Spectral surface albedo over Morocco and its impact on the radiative forcing of saharan dust. Tellus 61B, doi: 10.1111/j.16000889.2008.00395.x.

Catrall, C., Carder, K. L. and Gordon, H. R. 2003. Columnar aerosol single-scattering albedo and phase function retrieved from sky radiance over the ocean: measurements of Saharan dust. J. Geophys. Res. 108, 4287, doi: 10.1029/2002JD002497.

Dinter, T., von Hoyningen-Huene, W., Burrows, J. P., Kokhanovsky, A., Bierwirth, E. and co-authors. 2008. Retrieval of aerosol optical thickness for desert conditions using MERIS observations during SAMUM campaign. Tellus 61B, doi: 10.1111/j.1600-0889.2008.00391.x.

Dubovik, O. and King, M. D. 2000. A flexible inversion algorithm for retrieval of aerosol optical properties from sun and sky radiance measurements. J. Geophys. Res. 105, 20 673-20 696.

Dubovik, O., Holben, B. N., Lapyonok, T., Sinyuk, A., Mishchenko, M. I. and co-authors. 2002. Non-spherical aerosol retrieval method emploing light scattering by sheroids. Geophys. Res. Lett. 29, doi: 10.1029/ 2001 GL01506.

Dubovik, O., Sinyuk, A., Lapyonok, T., Holben, B. N., Mishchenko, M. and co-authors. 2006. Application of spheroid models to account for aerosol particle nonsphericity in remote sensing of desert dust. J. Geophys. Res. 111, D11208, doi: 10.1029/2005JD006619.

Heese, B., Althausen, D., Dinter, T., Esselborn, M., Müller, T., Tesche, M. and Wiegner, M. 2008. Vertically resolved dust optical proper- ties during SAMUM: Tinfou compared to Ouarzazate. Tellus 61B, doi: 10.1111/j.1600-0889.2008.00404.x.

Hess, M., Koepke, P. and Schult, I. 1998. Optical properties of aerosols and clouds: The software packege OPAC. Bull. Am. Meteorol. Soc. 79, 831-844.

Holben, B. N., Eck, T. F., Slutsker, I., Tanré, D., Buis, J. P. and coauthors. 1998. AERONETa federated instrument network and data archive for aerosol characterization. Remote Sens. Environ. 66, 1-16.

von Hoyningen-Huene, W. and Posse, P. 1997. Non-sphericity of aerosol particles and their contribution to radiative forcing. J.Quant. Spectr. Rad. Trans. 57, 651-668.

von Hoyningen-Huene, W., Wenzel, K. and Schienbein, S. 1999. Radiative properties of desert dust and its effect on radiative balance. J. Aeros. Sci. 30, 489-502.

Hsu, N. C., Tsay, S. C., King, M. D. and Herman, J. R. 2004. Aerosol properties over bright-reflecting source regions. IEEE TGRS 42, 557569.

IPCC, B. 2007. Climate change. The physical science basis. contribution of working group 1 to the fourth assessment report of the intergovernmental panel on climate change (IPCC). In: Climate Change 2007 (eds. A. S. Solomon, D. Qin, M. Manning, M. Marquis, K. Averyt, and co-editors. ) Cambridge University Press, Cambridge.

Kasten, F. and Young, A. T. 1989. Revised optical airmass tables and approximation formula. Appl. Opt. 28, 4735-4738.

Kinne, S., Akerman, T. P., Shiobara, M., Uchijama, A., Heymfield, A. J. and co-authors. 2000. Cirrus cloud radiative and microphysical properties from ground observations and in situ measurements during FIRE 1991 and their application to exhibit problems in Cirrus solar radiative transfer modeling. J. Atmos. Sci. 54, 2320-2344.

Levy, R. C., Remer, L. and Dubovik, O. 2007. Global aerosol optical properties and application to Moderate Resolution Imaging Spektrometer aerosol retrieval. J. Geophys. Res. 112, D13210, doi: 10.1029/2006JD007815.10.1029/2006JD007815.

Mishchenko, I. M., Travis, L. D. and Macke, A. 2000. T-Matrix method and its application. In: Light Scattering by Non-spherical Particles (eds. I.M. Mishchenko, J. W. Hovenier and L. D. Travis). Academic Press, San Diego, 147-173.

Müller, T., Schladitz, A., Maßling, A., Kaaden, N., Wiedensohler, A. and co-authors. 2008a. Spectral absorption coefficients and refractive index of Saharan dust during SAMUM-1. Tellus 61B, doi: 10.1111/ j.1600-0889.2008.00399.x.

Müller, D., Dubovik, O., Ansmann, A., Tesche, M., Weinzierl, B. and co-authors. 2008b. AERONET Sun photometer observations during SAMUM 2006: comparison of mineral dust optical and microphysical properties to results from lidar and airborne in-situ measurements. Tellus 61B, doi: 10.1111/j.1600-0889.2008.00400.x.

Nakajima, T. and Tanaka, M. 1988. Algorithms for radiative intensity calculations in moderately thick atmospheres using a truncation approximation. J. Quant. Spectrosc. Radiat. Transfer 40, 51-69.

Petzold, A., Rasp, K., Weinzierl, B., Esselborn, M. Hamburger, T. and co-authors. 2008. Saharan dust absorption and refractive index from aircraft-based observations during SAMUM 2006. Tellus 61B, doi: 10.1111/j.1600-0889.2008.00383.x.

Pollack, J. B. and Cuzzi, J. N. 1989. Scattering by nonspherical particles of size comparable to the wavelength: Aa semiempirical theory and its application to tropospheric aerosol. J. Atmos. Sci. 37, 868881. 
Russell, P. B., Livingston, J. M., Dubovik, O., Ramirez, S. A., Wang, J. and co-authors. 2004. Sunlight transmission through desert dust and marine aerosols: diffuse light corrections to Sunphotometry and pyrheliometry. J. Geophys. Res. 109, D08207, doi: 10.1029/ 2003JD004292.

Sokolik, I. and Toon, O. B. 1999. Incorporation of mineralogical composition into radiative models of radiative properties of mineral aerosol from UV to IR wavelength. J. Geophys. Res. 104, 9423-9444.

Tesche, M., Ansmann, A., Müller, D., Althausen, D., Mattis, I. and coauthors. 2008. Vertical profiling of Saharan dust with Raman lidars and airborne HSRL in southern Morocco during SAMUM. Tellus 61B, doi: 10.1111/j.1600-0889.2008.00390.x.
Volten, H., de Haan, J. F., Vassen, W., Lumme, K. and Hovenier, J. W. 1996. Experimental determination of polarized light scattering by irregular particles. J. Aerosol Sci. 27, 527-528.

Volten, H., Munoz, O., de Haan, J. F., Vassen, W., Hovenier, J. W. and co-authors. 2001. Scattering matrices of mineral aerosol particles at $441.6 \mathrm{~nm}$ and $632.8 \mathrm{~nm}$. J. Geophys. Res. 106, 17375-17 401.

Volz, F. 1954. Die Optik und Meteorologie der atmosphärischen Trübung. Berichte des Deutschen Wetterdienstes 2, 13.1-13.47.

Wendisch, M. and von Hoyningen-Huene, W. 1994. Possibility of refractive index determination of atmospheric aerosol particles by ground based solar extinction and scattering measurements. Atmos. Environ. 28, 785-795. 